\title{
Desenvolvimento de webtecnologia educacional sobre citologia clínica para estudantes e profissionais da área da saúde
}

\begin{abstract}
RESUMO | Objetivo: Descrever o processo de desenvolvimento de uma webtecnologia educacional, do tipo blog, sobre citologia clínica, para estudantes e profissionais da área da saúde. Métodos: Pesquisa metodológica para construção de tecnologia educacional em saúde, desenvolvida em três etapas: Revisão da literatura (2019), a partir da qual se deu o delineamento teórico; Fotodocumentação (2020), que foi a fase responsável pela obtenção do conteúdo imagético; Construção (2020-2021), a partir da qual se deu a criação do blog. Resultados: Na primeira fase, obteve-se a fundamentação teórica. Na segunda fase, realizou-se a obtenção das imagens e na terceira fase, o desenvolvimento do produto técnico-tecnológico. Conclusão: O blog, emerge como modelo de suporte para proporcionar um caráter de ubiquidade à informação e como consequência disso, ampliar o potencial gerador de conhecimento sobre citologia clínica entre estudantes e profissionais de diversos campos da área da saúde, com enfoque à Biomedicina e Enfermagem.
\end{abstract}

Descritores: Blog; Educação continuada; Teste de Papanicolaou; Tecnologias Educacionais.

ABSTRACT | Objective: To describe the development process of an educational webtechnology, like a blog, about clinical cytology, for students and health professionals. Methods: Methodological research for the construction of educational technology in health, developed in three stages: Literature review (2019), from which the theoretical outline was given; Photodocumentation (2020), which was the phase responsible for obtaining the image content; Construction (2020-2021), from which the creation of the blog took place. Results: In the first phase, the theoretical foundation was obtained. In the second phase, the images were obtained and in the third phase, the development of the technical-technological product. Conclusion: The blog emerges as a support model to provide a ubiquitous character to information and, as a consequence, expand the potential generator of knowledge about clinical cytology among students and professionals from different fields of health, with a focus on Biomedicine and Nursing

Descriptors: Blog; Continuing Education; Pap smear test; Educational Technologies

RESUMEN | Objetivo: Describir el proceso de desarrollo de una tecnología web educativa, como un blog, sobre citología clínica, para estudiantes y profesionales de la salud. Métodos: Investigación metodológica para la construcción de tecnología educativa en salud, desarrollada en tres etapas: Revisión de la literatura (2019), a partir de la cual se dio el esquema teórico; Fotodocumentación (2020), que fue la fase encargada de obtener el contenido de la imagen; Construcción (2020-2021), a partir de la cual tuvo lugar la creación del blog. Resultados: En la primera fase se obtuvo el fundamento teórico. En la segunda fase se obtuvieron las imágenes y en la tercera fase, el desarrollo del producto técnico-tecnológico. Conclusión: El blog surge como un modelo de apoyo para dotar de un carácter ubicuo a la información y, como consecuencia, ampliar el potencial generador de conocimiento sobre citología clínica entre estudiantes y profesionales de diferentes campos de la salud, con enfoque en Biomedicina y Enfermería

Descriptores: Blog; Educación contínua; Prueba de Papanicolaou; Tecnologías educativas.

\section{Célio Amoêdo de Melo}

Biomédico, Mestre em Análises Clínicas pela Universidade Federal do Pará, Docente do curso de Biomedicina e Coordenador do Programa de Pós Graduação (Nível Lato Sensu) em Citopatologia Oncótica com ênfase no trato genital feminino do Centro Universitário Fibra

ORCID: 0000-0003-4539-9230

\section{Murilo Tavares Amorim}

Biomédico, Mestrando em Biologia de Agentes Infecciosos e Parasitários pela Universidade Federal do Pará.

ORCID: 0000-0002-9769-2183

\section{Patrícia Bentes Marques}

Biomédica, Doutora em Biologia de Agentes Infecciosos e Parasitários pela Universidade Federal do Pará, Coordenadora do curso de Biomedicina do Centro Universitário Fibra.

ORCID: 0000-0003-0951-2822

\section{Elizabeth Teixeira}

Enfermeira, Doutora em Ciências: Desenvolvimento Socioambiental pela Universidade Federal do Pará, Docente do Programa de Pós Graduação em Análises Clinicas da Universidade Federal do Pará.

ORCID: 0000-0002-5401-8105

\section{Michele Amaral da Silveira}

Biomédica, Doutora em Neurociências e Biologia Celular pela Universidade Federal do Pará, Docente do curso de Biomedicina do Centro Universitário Fibra.

ORCID: 0000-0001-5119-7526

\section{Maísa Silva de Sousa}

Doutora em Ciências Biológicas: Genética e Biologia Molecular pela Universidade Federal do Pará, Docente do Programa de Pós Graduação em Análises Clínicas da Universidade Federal do Pará ORCID: 0000-0001-9944-7838

Recebido em: 27/08/2021 Aprovado em: 30/11/2021 
$\mathrm{O}$ processo de compreensão do ensino e da aprendizagem, enquanto propriedade fundamental à formação humana, coexiste de forma mútua, apresentando elementos distintos que se caracterizam como propriedades essenciais, tanto do indivíduo, quanto da disponibilidade dos produtos decorrentes do meio em que ele é submetido. Assim, ao longo dos anos, tem-se dado certa atenção aos modelos aplicados no desenvolvimento do conhecimento e da aprendizagem 1. Com ênfase na relação entre o indivíduo e o objeto de conhecimento, diversas teorias sobre como o processo de formação do homem ocorre são discutidas, a fim de remodelar uma conjuntura específica de ensino, a partir da distinção das principais posturas teórico-metodológicas aplicadas na atualidade $2,3$.

Ao considerar a universidade como uma instituição demarcada com a proposta de sistematização do conhecimento, é de fundamental importância a construção de alternativas e condições viáveis na promoção do ensino, baseado no fomento de alternativas distintas de modelos previamente instrumentalizados, que visem ao desenvolvimento teórico e prático da formação profissional. Logo, a capacitação de profissionais envolvidos com a identificação das lesões uterinas e o maior número e disponibilidade de protocolos podem ampliar as opções e viabilizar o diagnóstico precoce. A criação de novos conteúdos de referência pode proporcionar ao estudante e ao profissional uma nova forma de memorização das imagens e seus respectivos critérios de identificação 3, 4 .

Em associação com o desenvolvimento teórico e prático dos métodos ativos de ensino-aprendizagem, a universidade apresenta-se como um intermédio do desenvolvimento profissional permanente, principalmente em cursos da área da saúde, fundamentado na
Ao considerar a universidade como uma instituição demarcada com a proposta de sistematização do conhecimento, é de fundamental importância a construção de alternativas e condições viáveis na promoção do ensino, baseado no fomento de alternativas distintas de modelos previamente instrumentalizados, que visem ao desenvolvimento teórico e prático da formação profissional competência profissional, integrado na dimensão dialógica, possibilitando o reconhecimento do contexto social no qual o profissional está inserido 5,6. Portanto, alguns aspectos da formação de estudantes e profissionais necessitam de condições favoráveis no sentido de possibilitar uma formação continuada, de modo a incentivar novas perspectivas de ensino baseadas nas estruturas metodológicas mais atuais 7,8 .

O desenvolvimento da competência profissional, em uma sinergia do papel do docente junto à universidade, estrutura-se nessa esfera, que converge na formação de profissionais, nesse âmbito em particular, da área da saúde 8. Os domínios afetivos, cognitivos e psicomotores podem se estabelecer como um regulador altamente variável nesse viés, uma vez que a transformação da realidade proposta ao indivíduo, pode submetê-lo a novos desafios, tornando-o capaz de responder de forma ativa a dificuldades que possa encontrar no ambiente laboral. Assim, em virtude da necessidade de uma formação profissional compromissada com a sociedade e a prestação de serviços de qualidade, tem-se requerido cada vez mais profissionais com prática integral e de permanente aprendizagem 9, 10.

Todos os processos de ensino objetivam viabilizar a aprendizagem para o indivíduo que, em uma esfera de multiplicidade de sujeitos, saberes, espaços e tempos, devem ser tidos como prioridade. Portanto, em áreas que exigem uma acurácia inteiramente específica do profissional, como se observa nos cursos da saúde, faz-se necessária a compreensão dos modelos educativos de forma crítica e sistematizada a partir do reconhecimento das relações existentes entre educação, sociedade e teorias pedagógicas 11. Desse modo, oportunizar o uso de blogs na esfera educacional trata-se também de incentivar o desenvolvimento de habilidades e de contextos interativos na construção de trajetórias e experiências im- 
prescindíveis no contexto laboral 12, 13.

Nesse espectro, a citologia clínica baseada no enfoque da identificação morfológica de estruturas celulares, exige uma compreensão integrada e fundamentada em sistemas de ensino organizados, que viabilizem uma aprendizagem substancial, associada à manipulação adequada do método de ensino e do produto didático ideal para a transmissão do conhecimento. Acredita-se, então, que deve ser estimulada a interação entre a estrutura prévia cognitiva do indivíduo e o conteúdo de aprendizagem, a fim de propiciar um processo de ressignificação mútua do núcleo do conhecimento adquirido, crucial para desenvolvimento das habilidades técnicas do profissional 14, 15.

A compreensão dos aspectos inerentes às dificuldades da formação profissional, se correlaciona com o papel do educador e do acompanhamento da instituição nesse processo. Assim, em virtude dos aspectos inerentes às dificuldades na compreensão da citologia clínica, é provável que as tecnologias possam traduzir mudanças na forma como esse ensino pode ser disseminado, a partir da utilização de suas ferramentas de acesso como instrumentos de inovação em ensino, possibilitando a construção e a atualização de conhecimentos 13. Diante da necessidade de uma formação continuada aprimorada, com enfoque na formação do profissional para a prática, pode-se pensar na estruturação de ações que o confiram habilidades no ordenamento, na síntese e na identificação de estruturas celulares em citologia clínica 16. O objetivo do estudo é descrever o processo de desesenvolvimento de uma webtecnologia educacional, do tipo blog, sobre citologia clínica, para estudantes e profissionais da área da saúde.

\section{MÉTODOS}

Trata-se de uma pesquisa meto- dológica de construção de tecnologia educacional em saúde 17, desenvolvida em três etapas: (I) Revisão da literatura; a partir da qual se deu o delineamento da tecnologia, realizada durante o ano de 2019; (II) Fotodocumentação; a part; ir da qual se deu o delineamento do conteúdo, com realização durante o primeiro e segundo trimestre do ano de 2020; (III) Construção do Produto; a partir do qual se deu a criação do blog, desenvolvido no terceiro e quarto tri- mestre do ano de 2020 e primeiro semestre do ano de 2021.

Inicialmente, foi desenvolvida uma revisão bibliográfica que objetivou descrever o conteúdo disponível na literatura acerca do uso das tecnologias educacionais como ferramentas integrativas de complementação na formação de estudantes e profissionais da área da saúde, com vistas acorroborar para a promoção do ensino em saúde e promover alternativas viáveis e aces-

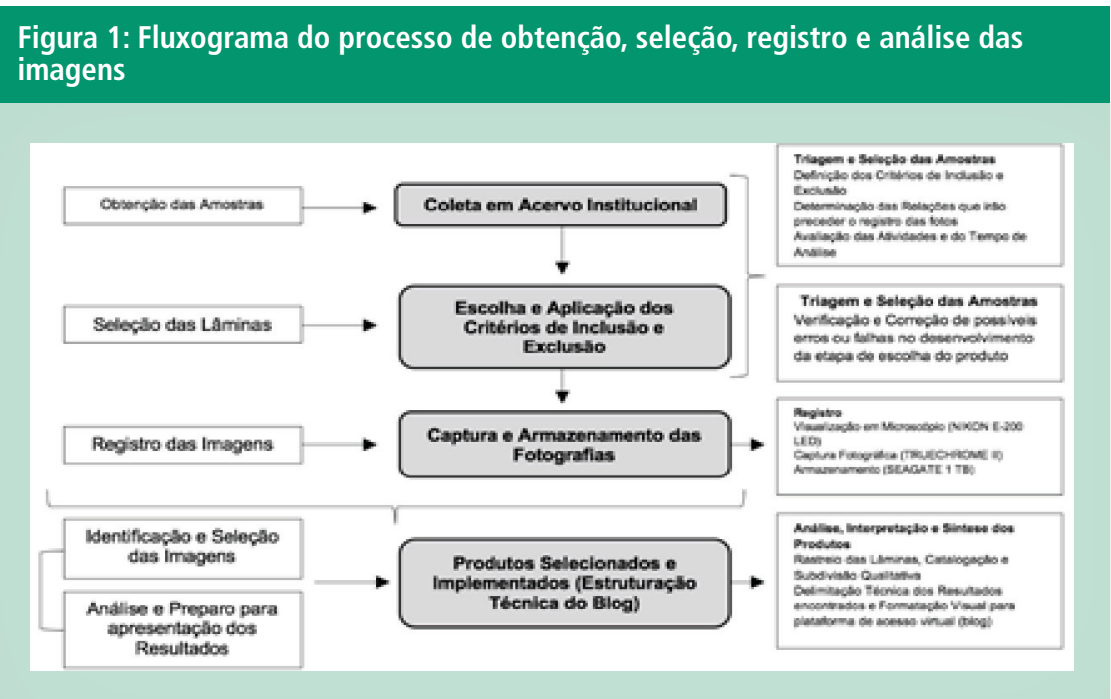

Fonte: Autoria Própria, 2021

Figura 2: Fluxograma de Criação, Desenvolvimento e Edição do Blog

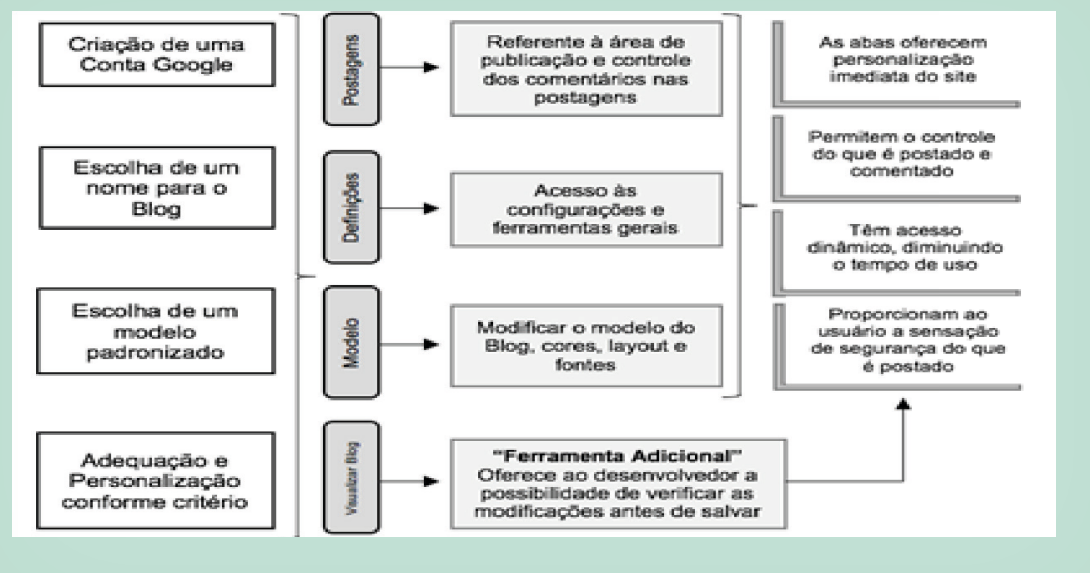

Fonte: Autoria Própria, 2021 
síveis no desenvolvimento de métodos educacionais em citologia clínica. O estudo compreendeu a primeira etapa de desenvolvimento teórico aplicado à construção de Webtecnologia, mediada a partir de uma revisão bibliográfica do tipo integrativa, de base observacional e de natureza qualitativa, fundamentada por meio de estudos que reiteram temas acerca de tecnologias educacionais como ferramentas para o desenvolvimento profissional na área da saúde. Mais detalhes estruturais sobre o modelo metodológico está disponibilizado em Melo \& Sousa (2021)18.

Em virtude da variedade de recomendações existentes para um bom registro fotográfico possuir parâmetros incipientes e rasos na literatura especializada, estando algumas relacionadas a parâmetros convergentes e outros divergentes, utilizou-se as recomendações descritas a partir de referências protocolares de modo a garantir a fidedignidade no registro e manutenção das imagens 19, 20. O material citológico utilizado para a fotodocumentação foi obtido de lâminas de raspados cérvicos-vaginais, corados pela técnica de Papanicolaou. As lâminas foram provenientes do arquivo institucional do Laboratório de Citopatologia do Instituto de Ciências Biológicas da Universidade Federal do Pará. Após análise prévia, foram selecionadas 200 lâminas para a seleção de campo para compor o arquivo de fotos. Foram excluídas aquelas com mais de 3 anos, por perda da coloração, desgaste da lâmina (quebradas, ressecadas ou rachadas) e com excesso de piócitos e/ou hemácias.

Para obtenção das imagens, as lâminas foram analisadas em microscópio Nikon E-200 - LED, nas objetivas de 10 e 20 vezes. As áreas selecionadas para fotografia foram marcadas na lâmina com caneta do tipo permanente 2.0, capturadas pela câmera fotográfica TrueChrome II, catalogadas e arquivadas em HD externo, Seagate 1 TB, para posterior seleção. As fotos foram docu- mentadas de acordo com a qualidade da imagem. Foram utilizadas lâminas com esfregaços de boa qualidade didática, que atendessem aos objetivos da pesquisa. O registro e a análise dos objetos de estudo foram realizados no Laboratório de Microscopia e Projeção Microscópica do Centro Universitário

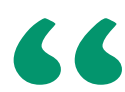

\section{A compreensão dos aspectos inerentes às dificuldades da formação profissional, se correlaciona com o papel do educador e do acompanhamento da instituição nesse processo}

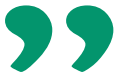

Fibra. A Figura 1 ilustra o processo de seleção prévia das amostras para posterior armazenamento, registro, análise e apresentação dos resultados propostos.

Ao final desse processo, foram extraídas as imagens necessárias para complementação da webtecnologia, responsável por compor a base técnica do produto educacional, de modo a fornecer a estrutura do resultado final.

Etapa 3: Construção do produto

A construção do produto tecnoló- gico educacional (blog) se deu com a materialização do desenho do estudo, a partir do que foi exposto na etapa 1 e na etapa 2 de desenvolvimento. Utilizou-se um sistema de elaboração secundária, pela utilização do site Blogger, hospedado na plataforma de acesso virtual Google, seguindo um delineamento pré-determinado pelos algoritmos do site, o que forneceu um detalhamento de sequência do tutorial, da estrutura de navegação, da interface e do layout do Blog.

A construção do Blog se deu em linguagem HTML (Hyper Text Makup Language), Javascript, CSS e o framework Bootstrap por apresentarem-se como linguagens de fácil compreensão, simplicidade, clareza e objetividade, além de evitar a criação de links de acesso longos e de difícil compartilhamento. Essas linguagens foram escolhidas por tornar os conteúdos mais acessíveis aos usuários, permitindo que eles compartilhem o conteúdo com maior facilidade e, como consequência, aprendam e avancem nos estudos com maior facilidade. Além disso, o sistema de escolha Blogger também oferece ferramentas para edição e gerenciamento. Portanto, será disponibilizado on-line, utilizando a ferramenta da Web 2.0 no endereço: https://citologiadiferenciada.blogspot. com. A criação do blog seguiu o tutorial disponível no site, com um fluxo de elaboração esquematizado na Figura 2.

Ao final desse processo, obteve-se o produto final, em conjunto com as inclusões das imagens e comentários no Blog, a fim de informar e disseminar o conhecimento científico, colaborando assim para a formação de profissionais da área da saúde.

\section{RESULTADOS}

Os resultados encontrados, tratam principalmente da necessidade da mudança na forma de aprendizagem, fundamentado na adaptação aos novos meios e tecnologias para o sistema 
de educação superior. De acordo com as tendências observadas no meio de ensino, as mudanças nos requisitos da educação e da sociedade têm sido amplamente discutidasna literatura. A adesão dessas tecnologias deve ampliar o potencial gerador de conhecimento, além do desenvolvimento de estudantes de citologia clínica, revolucionando o papel do profissional e traduzindo novas mudanças na prática do ensino em citologia. Detalhes e apresentação dos estudos podem ser observados em Melo \& Sousa (2021)18.

Cada imagem apresenta sua explicação citomorfológica em forma de texto, seguindo os critérios para laudos cervicais 21. Comentários das imagens serão permitidos para facilitar uma meIhor interação entre o estudante e o professor (Figura 3, 4 e 5).

A página inicial contém o nome do Blog e uma breve descrição das suas funções, cujo objetivo é facilitar o reconhecimento das células endocervicais, visto que, ao serem depositadas em lâminas por meio de esfregaços manuais, as mesmas adquirem vários formatos, tipos de grupamentos ou mesmo apresentam-se isoladas. Possui uma breve descrição das principais características anatômicas, histológicas e citológicas do trato genital femino. As imagens destacadas na página inicial, são autorais e têm o objetivo de introduzir conceitos básicos ao tema proposto. Para acesso ao Blog, pode-se utilizar o endereço https://citologiadiferenciada. blogspot.com, o acesso também pode ser viabilizado ao apontar o leitor do dispositivo móvel para o QR Code (Figura 6).

Ainda na página inicial, o usuário contará com a ferramenta de "Links Úteis", que redireciona automaticamente para sites de referência (Sociedade Brasileira de Citologia; Instituto Nacional do Câncer; Histopatologia e Citopatologia do Colo Uterino - Atlas Digital; Sociedade Brasileira de Citologia Clínica; Nomenclatura Para Laudos

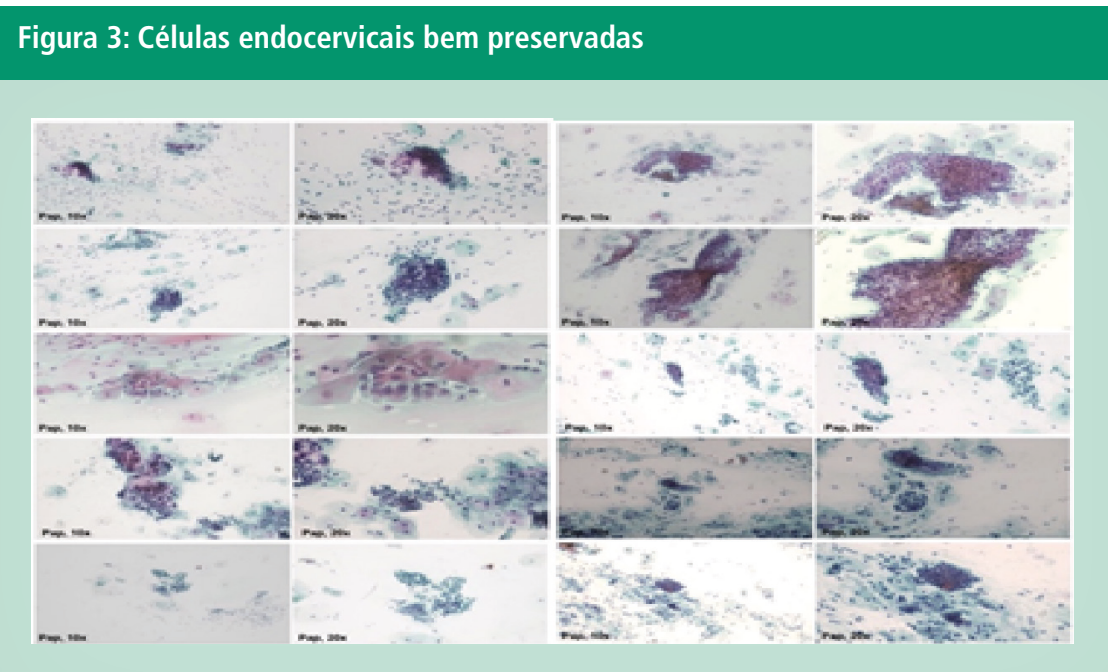

Fonte: Autoria Própria, 2021

\section{Figura 4: Células endocervicais em processo de degeneração}

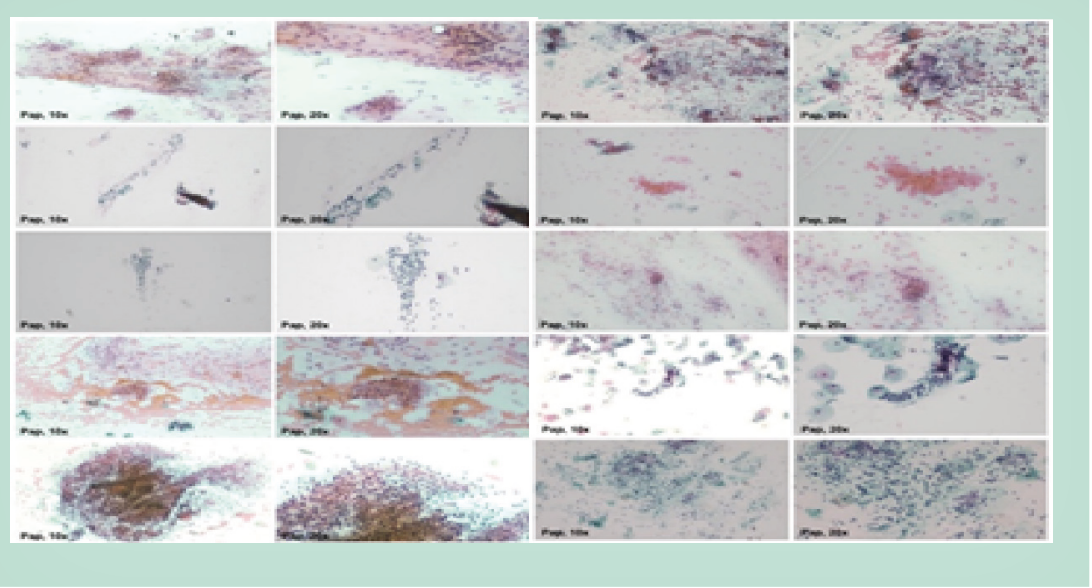

Fonte: Autoria Própria, 2021

Citológicos; Diretrizes brasileiras para o rastreamento do CCU; Manual de Gestão da Qualidade para Laboratório de Citopatologia). A escolha destes sites se deu conforme critério do autor, a partir do conteúdo mais utilizado no desenvolvimento das aulas do docente, por se tratar de fontes confiáveis e de referência na área.

O Blog Citologia Diferenciada foi setorizado de acordo com as categorias de cada grupo celular que poderá ser observado: Células Endocervicais bem preservadas; Células Endocervicais em processo de degeneração; Células Endocervicais degeneradas. Cada categoria conta com vinte imagens, sendo dez em menor aumento (10x) e dez em maior aumento (20x). O usuário deve acessar os links que se encontram na página inicial na sessão "Categorias", ou ainda, poderá fazer uso da ferramenta de procura (localizada acima da sessão categorias), usando qualquer palavra-chave relacionada. Essa ferramenta de busca permite acesso rápido a qualquer conteúdo do blog, garantido flexibilidade e rapidez no uso da 
Figura 5: Células endocervicais degeneradas

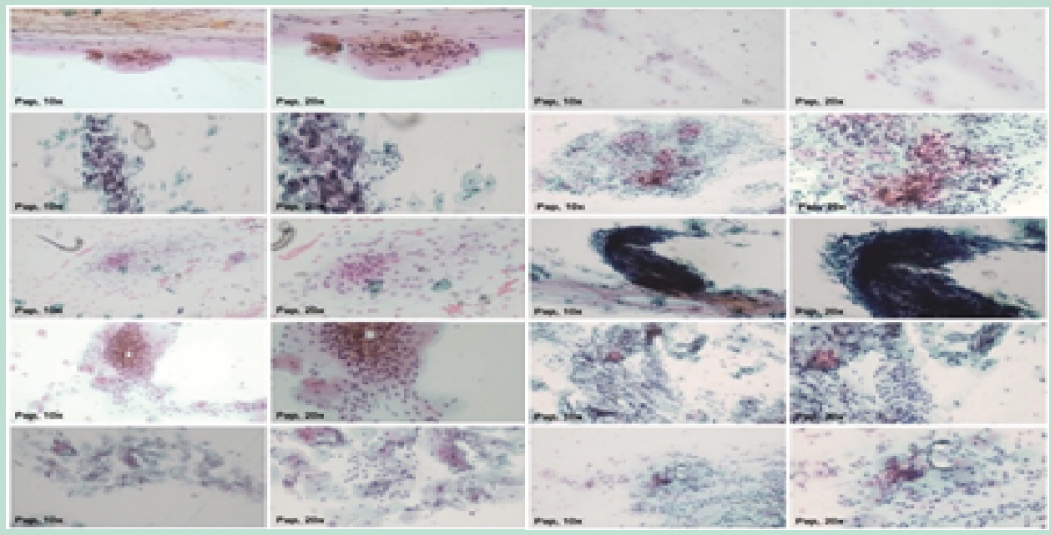

Fonte: Autoria Própria, 2021

\section{Figura 6: Página inicial e QR Code de acesso ao Blog Citologia Diferenciada}
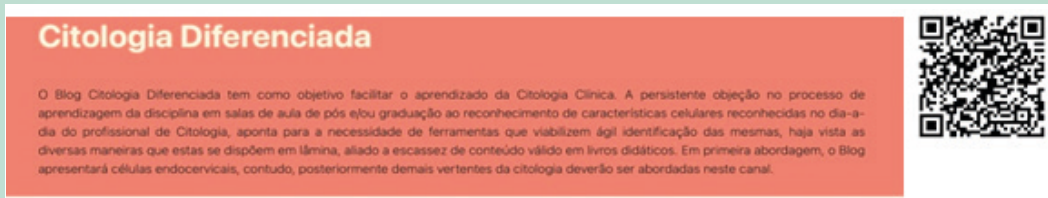

\section{Anatomia, histologia e citologia do Trato} Genital Feminino

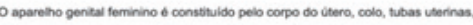

ovarios, canal raginas (Fig, 1 )

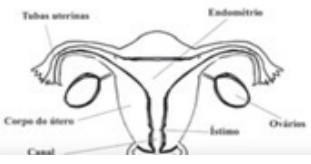

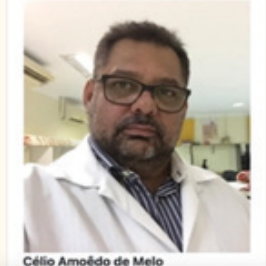

Amotdo de velo

Fonte: Blog Citologia Diferenciada, Disponível em: https://citologiadiferenciada.blogspot

plataforma durante a navegação.

Ao selecionar a categoria desejada, o usuário é direcionado à página que contém a galeria de imagens pertencente ao respectivo grupo. Ao clicar em cada imagem, conforme descrita na fotodocumentação, o usuário é direcionado à página que possui a descrição de cada lâmina e os aspectos citológicos mais relevantes. Ainda na página da imagem selecionada no acervo imagético, o usuário do blog terá a possibilidade de deixar um comentário, podendo o discente respondê-lo, gerando interação e feedback entre o corpo acadêmico. Este espaço será destinado para inserção de dúvidas e compartilhamento de ideias e compreensão entre o próprio grupo de alunos, a fim de facilitar o aprendizado. Tal recurso apresenta ampla utilidade por permitir contato direto e discussão de conteúdos

Para a interação entre o autor do blog e os usuários, estes serão redirecionados para uma página onde serão permitidas as utilizações de tags, por meio do login na conta Google. Para finalização da postagem do comentário, o usuário passará por uma autenti- cação via reCAPTCHA, a fim de evitar comentários fraudulentos de hackers por robôs. Após este procedimento, o usuário poderá clicar em "postar um comentário". Além disso, o rodapé do blog apresenta um gráfico para visualização da quantidade de acessos ao site e ferramentas de navegação: postagem mais recente, mais antiga e página inicial

\section{DISCUSSÃO}

Considerando os métodos de aprendizagem encontrados na literatura e comparados ao cenário da teoria e da prática profissional, na área da saúde, sob seus princípios e diretrizes, pôde-se observar que há em seu componente estrutural um conjunto de requisitos fundamentais para a identificação das necessidades da saúde e cuidado centrado no paciente. Assim, de modo a promover uma aprendizagem significativa e concatenada no processo contínuo de formação, diversos modelos de ensino com enfoque na evolução técnica do profissional, tem sido utilizados a fim de favorecer seu processo interno de construção profissional. Em virtude disso, estudos tem sido desenvolvidos com a proposta de compreender os desafios propostos, e respondê-los, na busca por métodos eficazes de ensino que compreendam as necessidades da contemporaneidade 13, 22, 23.

O blog permitiu que os estudantes e profissionais pudessem interagir de forma contínua, oferecendo uma contribuição mútua entre os usuários e, esse modelo de webtecnologia, quando devidamente planejado e estruturado, pode servir como uma ferramenta pedagógica de ensino em disciplinas que exigem uma formação continuada e aprimorada no desenvolvimento de estratégias de formação 12, 24. O Blog Citologia Diferenciada se propôs a apresentar células endocervicais, por apresentarem características diferenciadas, dentre os achados citológicos. 
No entanto, pretende-se, que em breve sejam abordadas as demais vertentes da Citologia Clínica neste canal. Haja vista o amplo espaço que a temática aborda, além das benesses advindas da webtecnologia, a qual poderá ser uma ferramenta eficaz para a mitigação das falhas do processo ensino-aprendizagem.

Desse modo, o produto desenvolvido se estabelece como um modelo de tecnologia educacional que busca somar à promoção do ensino em saúde, para alunos e profissionais, além de promover uma alternativa viável e acessível que incentive o desenvolvimento de produtos semelhantes, caracterizando como um modelo inovador no que tange à ampliação de competências, por meio da autonomia e da criatividade proporcionada pela utilização do blog. Assim, em meio ao fomento da disseminação a propostas que viabilizem o conhecimento para os profissionais da área da saúde, deve ser atribuído destaque ao Centro Universitário Fibra, como instituição parceira no processo de desenvolvimento desse estudo, que forneceu todos os meios necessários para a construção do produto final.

\section{CONCLUSÃO}

Em uma primeira abordagem, o Blog Citologia Diferenciada se apresenta como um produto tecnológico com espectro inovador na área da saúde. Como um produto autoral e diante das dificuldades observadas no ensino após anos e experiência, a proposta, caracterizada como uma forma de transformação digital aplicada ao ensino, corresponde como modelo de suporte para proporcionar um caráter de ubiquidade à informação e como consequência disso, ampliar o potencial gerador de conhecimento, além do desenvolvimento profissional de estudantes de citologia clínica.

Nessa perspectiva, o estudo propôs apresentar os aspectos morfológicos das células endocervicais, por apresentarem características diferenciadas, dentre os achados citológicos. No entanto, pretende-se, que em breve sejam abordadas as demais vertentes da $\mathrm{Ci}$ tologia Clínica. Haja vista o amplo espaço que a temática aborda, além das benesses advindas da webtecnologia, a qual poderá ser uma ferramenta eficaz para a mitigação das falhas do processo ensino-aprendizagem sobre o tema, pois, quando feito o levantamento de artigos, foi notória a dificuldade na busca de artigos relacionadas ao tema.

Além disso, o estudo pôde mostrar que a compreensão das células do trato genital feminino é um expoente de grande relevância no âmbito do ensino na área da saúde. A dificuldade inerente à compreensão do estudo morfológico das alterações celulares foi um aspecto observado durante a realização do trabalho e o Centro Universitário Fibra, enquanto instituição parceira, permeou o processo de desenvolvimento do produto final. Assim, esse estudo espera contribuir com o rastreamento do Câncer de Colo Uterino a partir da capacitação de profissionais envolvidos com a identificação das lesões uterinas.

Para isso, o desenvolvimento de recursos digitais pode contribuir com a padronização da morfologia celular. Assim, a educação pode se beneficiar desta ferramenta, utilizando os blogs de ensino como estratégia pedagógica para construção do conhecimento. A construção do Blog "Citologia Diferenciada" pode contribuir para uma melhor elucidação acerca da citologia clínica, além de estreitar laços entre docentes e discentes, através de feedback entre as partes, pela interação virtual.

\section{Referências}

[1] Alexandre, S. F. Aprendizagem E Suas Implicações No Processo Educativo. Revista De Letras Da Ueg. São Luís De Montes Belos, p. 51-60, 2010.

[2] Palangana, I. C. Desenvolvimento E Aprendizagem Em Piaget E Vigotsky (A Relevância Do Social). Editora: Plexus - 2ª Edição. 1998.

[3] Santos, S. C. S. C; Kaulfuss, M. A. Processo De Ensino Aprendizagem No Contexto Escolar: Dificuldades E Transtornos De Aprendizagem. Editora Plexus, 1997.

[4] Gasparin, J. L. Uma Didática Para A Pedagogia Histórico-Crítica. 3 Ed. Campinas: Autores Associados, 2015.

[5] Chirelli, M. Q; Pio, D. A. M; Soares, M. O. M. Competência Dialógica: Avaliação Do Desempenho No Currículo Integrado. Indagatio Didactica, v. 8, n. 3 p. 109-123, 2016.

[6] Lakatos, E.; Marconi, M. Fundamentos De Metodologia Científica. São Paulo: Atlas, 2001

[7] Ghiraldelli J, P. Didática e Teorias Educacionais. Rio de Janeiro: Dp\&A,
2000

[8] Zamunaro, A. M. B. R. A Prática De Ensino De Ciências e Biologia e Seu Papel na Formação De Professores. Bauru: Universidade Estadual Paulista, p. 236, 2006

[9] Stelet, B. P. et al. Reflective Portfolio: Philosophical Contributions to a Narrative Praxis In Medical Education. Interface (Botucatu), v. 21, n. 60, p. 165-176, 2017.

[10] Santos, J. S.; Lacerda, N. A. A Linguagem Dos Alunos Na Escrita Colaborativa Em Blog Educacional Para 0 Ensino-Aprendizagem De Língua Portuguesa. Letras, Linguística E Artes: Perspectivas Críticas E Teóricas, [S.L.], v. 108, 2019.

[11] Lacanallo. C. D et al. Métodos de Ensino e de Aprendizagem: Uma análise histórica educacional do Trabalho Didático, e. 2, v. 12, Ed. Pensamento E Linguagem, 2019.

[12] Tacca, M. C. V. R., Branco, A. U. Processos De Significação Na Relação 


\section{Referências}

Professor-Alunos: Uma Perpsctiva Sociocultural Construtivista. Estudos De Psicologia, v. 13, n. 1, p. 39-48, 2018.

[13] Silveira, A. C. M. Da. (Org.). Divulgação Científica E Tecnologias De Informação E Comunicação. Santa Maria: Facos, UFSM, 2003.

[14] Mortimer, E.F.; Chagas, A.N.; Alvarenga, V.T. Linguagem Científica versus Linguagem Comum nas Respostas Escritas. Investigações em Ensino de Ciências, Porto Alegre, v.3, n.1, 1998.

[15] Castel, A. F. G. La Integración de las TIC en los procesos educativos y organizativos a integração das TIC nos processos educacionais e organizativos. Educar Em Revista, v. 34, n. 69, p. 325-339, 2018.

[16] Domingos, G. A. Dificuldades do Processo de Aprendizagem. p. 1-29. (Monografia) - Escola Superior Aberta Do Brasil. Vila Velha. p. 5, 2017.

[17] Nietsche, E. A. Tecnologias Educacionais, Assistenciais e Gerenciais: Uma Reflexão a Partir da Concepção dos Docentes de Enfermagem. Revista Latino-Americana De Enfermagem, [S.L.], v. 13, n. 3, p. 344-352, 2005.

[18] Melo, C. A. De; Sousa, M. S. de. Educational technology as an integra- tive complementary strategy in the training of students and professionals in the health area: Integrative review. Research, Society and Development, [S. I.], v. 10, n. 10, p. e87101018796, 2021.

[19] Diniz, A. A Iluminação Na Fotografia. Revista Especialize On-line IPOG. Goiânia, v. 1, n. 9, p. 1-17, 2004.

[20] Instituto Nacional De Câncer José de Alencar Gomes Da Silva (Brasil). Nomenclatura Brasileira para laudos citopatológicos cervicais. $3^{\mathrm{a}} \mathrm{Ed}$. Ministério Da Saúde. Rio De Janeiro: INCA, 2012.

[21] Nalom, D. et al. Ensino Em Saúde: Aprendizagem A Partir Da Prática Profissional. Ciência \& Saúde Coletiva. V. 24. P. 1699-1708, 2019.

[22] Fabrício, B. F Repetir-Repetir até ficar diferente": Práticas Descoloniais em um Blog Educacional. Cadernos De Linguagem E Sociedade, [S.L.], v. 18, n. 2, p. 9-26, 2017.

[23] Viana, G. M. Atlas Digital no Auxílio e Aprendizado de Histologia e de Citologia. Fórum De Ensino, Pesquisa E Extensão, 2017. 